\title{
The Scar Bane, Without the Pain: A New Approach in the Treatment of Elevated Scars: Thermomechanical Delivery of Topical Triamcinolone Acetonide and 5-Fluorouracil
}

\author{
Ofir Artzi · Amir Koren - Roni Niv · Joseph N. Mehrabi • \\ Or Friedman iD
}

Received: March 9, 2019 / Published online: April 30, 2019

(c) The Author(s) 2019

\begin{abstract}
Introduction: Keloids are challenging to treat due to their inadequate response to treatment and high recurrence rate. Intralesional triamcinolone acetonide (TAC) injection with or without 5-fluorouracil (5FU) is considered the first-line treatment for keloids. Three significant disadvantages of intralesional injections are the pain associated with the procedure, the uneven topography, and epidermal atrophy. Fractionated ablative carbon dioxide $\left(\mathrm{CO}_{2}\right)$ laser-assisted drug delivery (LADD) of the topical solution can help facilitate transdermal drug delivery and shows promise in scar remodeling. This study examined the use of a thermomechanical
\end{abstract}

Enhanced Digital Features To view enhanced digital features for this article go to https://doi.org/10.6084/ m9.figshare.7987415.

O. Artzi · A. Koren

Department of Dermatology, Tel Aviv Sourasky

Medical Center, Tel Aviv, Israel

O. Artzi · A. Koren · R. Niv

Dr. Artzi Treatment and Research Center, Tel Aviv, Israel

J. N. Mehrabi · O. Friedman

Sackler Faculty of Medicine,

Tel Aviv University, Tel Aviv, Israel

O. Friedman $(\square)$

The Plastic Reconstructive Surgery Department,

Tel Aviv Sourasky Medical Center, Tel Aviv, Israel e-mail: or.friedman@gmail.com device (Tixel, Novoxel) to facilitate the transdermal delivery of TAC and 5-FU in the treatment of keloid scars.

Methods: Seven patients each received eight topical thermal ablations, with one ablation performed every 2-3 weeks. TAC and 5FU were applied after each ablation. Outcomes were evaluated using the Vancouver Scar Scale (VSS), and pain was assessed using the Visual Analog Scale (VAS).

Results: Mean keloid VSS reduced from $8.6 \pm 1.2$ to $5 \pm 2.7$ after the eight treatments. Mean treatment pain VAS score was $2.4 \pm 0.7$. Patients rated their satisfaction level as moderate-high. No severe adverse reactions were noted.

Conclusion: Thermomechanical drug delivery of TAC and 5-FU is safe and effective. This is a promising option for the treatment of keloid scars, particularly in the pediatric population.

Keywords: Keloid; Fluorouracil; Fractional skin ablation; Percutaneous permeating; Resurfacing; Scar; Tixel; Transdermal drug delivery; Triamcinolone

\section{INTRODUCTION}

Keloid scars are an uncommon but severe result of impaired wound healing. Keloid scars may develop after acne vulgaris, trauma, surgical incisions, burn injuries, or without an obvious 
trigger $[1,2]$. Intralesional corticosteroid injection is considered the first-line treatment for keloid scars [3, 4]. Combination therapies with other adjuvant therapeutic modalities, such as pressure garments, silicone gel, radiation, or cryotherapy, seem to further increase treatment efficacy [5-7]. Complications associated with intralesional corticosteroid injection include tissue atrophy, hypopigmentation, hyperpigmentation, telangiectasia, and severe pain during the injection, perhaps due to random deposition within the scar if the corticosteroid follows the path of minimal resistance [8-10].

In recent years, laser-assisted drug delivery has been suggested as a means to overcome some of the complications associated with intralesional injections [11-14].

The aim of the present study was to explore the use of thermal decomposition of the stratum corneum to increase skin permeability for topical corticosteroid and 5FU application in the treatment of keloid scars.

\section{METHODS}

A retrospective review of 7 patients (4 males, 3 females) treated for keloid scars between January 2015 and December 2017 was performed. Patients were offered Tixel treatment following the failure of other modalities and their refusal of other options. Written consent was received after they had been informed of the nature of the procedure. Consent included the use of photos and data for teaching and in medical publications.

The patient's affected areas were treated with Tixel technology (Novoxel Ltd., Israel), which combines thermal energy with motion. The system consists of a titanium tip heated to $400{ }^{\circ} \mathrm{C}$. The tip is advanced until it makes contact with the skin. The tip therefore exerts an ablative effect on the skin due to physical contact and the transduction of heat to the superficial layers of the skin, as opposed to laser energy, which targets chromophores within the skin and heats them.

The tip was heated to $400{ }^{\circ} \mathrm{C}$ and contact with the skin was made just once (i.e., a single "pulse") for a duration of 5-8 ms. A protrusion (the distance the heated tip is moved beyond the edge of the handpiece distance gauge) of $1000 \mu \mathrm{m}$ was applied. Immediately after skin treatment, triamcinolone acetonide $(40 \mathrm{mg} / \mathrm{ml})$ and 5-fluorouracil $(50 \mathrm{mg} / \mathrm{ml})$ mixed in the ratio $1: 9$ were applied topically to the treatment area at a dose of $1 \mathrm{cc}$ per $\mathrm{cm}^{2}$ with no occlusion or bandaging. All scars received 8 treatments performed 2-3 weeks apart. Post-procedure care included topical trolamine (Biafine; Genmedix Ltd., France) applied by the patient 3-4 times a day for 3 days, as well as the use of a broadspectrum sunscreen with a sun protection factor (SPF) of 50 for 3 months.

The scars were evaluated and photographed at baseline and 2-3 months after the last treatment. Scars were evaluated by two independent dermatologists using the Vancouver Scar Scale (VSS). Pain levels were assessed according to the Visual Analog Scale (VAS), while satisfaction was assessed using a four-point scale ( 0 -not satisfied, 1-mildly satisfied, 2-moderately satisfied, 3-highly satisfied).

Statistical analysis was performed using SPSS software (version 21.0; IBM Corporation, Armonk, NY, USA).

\section{RESULTS}

Mean keloid VSS reduced from $8.6 \pm 1.2$ to $5 \pm 2.7(p=0.001)$. Mean pain VAS score was $2.4 \pm 0.7$. Overall, patients rated their satisfaction level as moderate-high. No severe adverse reactions were noted. According to their VSS score, 1 patient did not respond to treatment (Table 1).

\section{DISCUSSION}

Keloid scars are an uncommon but troubling complication of dermal injury, with a predilection for younger patients and higher Fitzpatrick skin types, particularly patients of African, Asian, or Hispanic origin with an associated family history [1-3]. Intralesional corticosteroid injections are considered the first-line treatment for keloids [3, 4]. Corticosteroids can be used alone or in combination with other scar- 


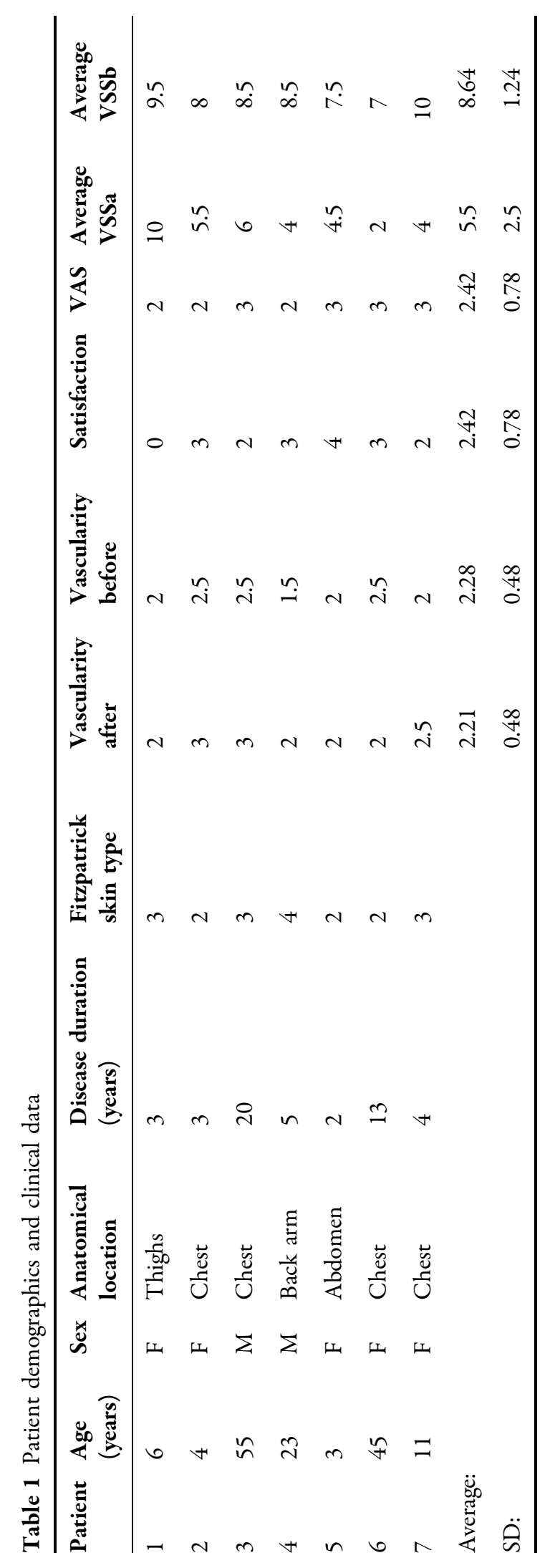




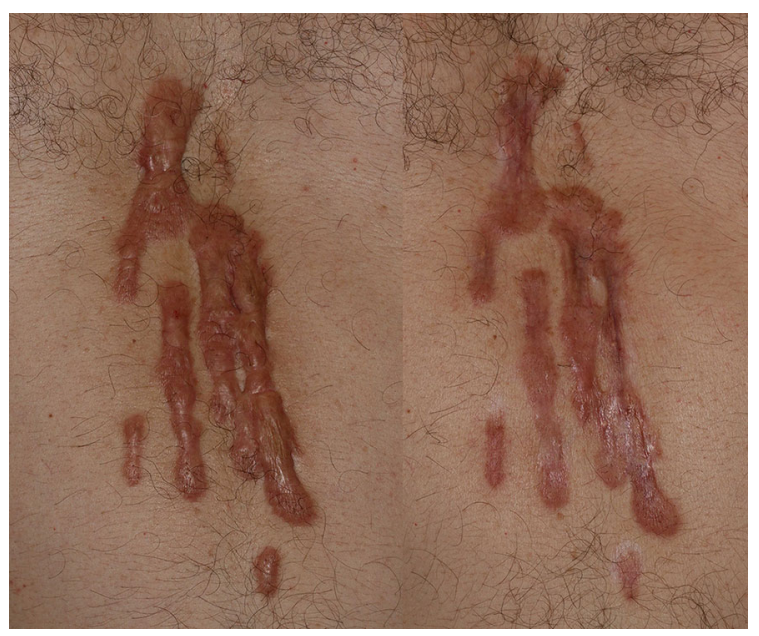

Fig. 1 Patient 3. Photographs of the keloid taken before treatment (left) and 3 months after the completion of eight treatment sessions (right)

modulating treatments such as intralesional 5-fluorouracil injection, cryotherapy, surgical excision, radiation therapy, compression therapy, and silicone-based dressings [5-7]. Potential adverse events associated with intralesional corticosteroid injection include dermal and subcutaneous atrophy, pigmentary alterations, and telangiectasia [8]. Also, the treatment is considered painful, which is a significant drawback, especially in pediatric patients $[9,10]$.

Fractionated ablative carbon dioxide $\left(\mathrm{CO}_{2}\right)$ laser-assisted drug delivery (LADD) of corticosteroids is considered less painful and distributes the drug more uniformly, and its use has resulted in encouraging clinical results $[11,12]$. LADD facilitates corticosteroid delivery through the microscopic channels created by the ablative fractional laser [12-14]. That said, LADD is not pain-free and it cannot be tolerated by a significant number of patients.

The therapeutic efficacy of a topical drug relates to both its inherent potency and its ability to penetrate the different skin layers. The main barrier to drug permeation is its passage through the stratum corneum [15]. The importance of the water content of the stratum corneum in determining its properties is well documented. The water content of the skin gradually increases upon moving from the upper layer of the stratum corneum down to the viable epidermis, where the water content remains almost constant with depth [16, 17]. The mechanical properties of the stratum corneum are strongly affected by the relative humidity (RH\%) within the layer. The breaking strength of the stratum corneum increases from about $10 \mathrm{~g}$ at $80-100 \% \mathrm{RH}$ to $45 \mathrm{~g}$ at $0 \% \mathrm{RH}$, while the elongation at break decreases from $200 \%$ at $100 \% \mathrm{RH}$ to less than $10 \%$ at $0 \% \mathrm{RH}$ [18].

Tixel technology combines thermal energy with motion. The system consists of a titanium tip heated to $400^{\circ} \mathrm{C}$. The tip is advanced until it makes contact with the skin, and the duration of this contact (the pulse duration) determines the amount of thermal energy delivered to the skin. The system provides the user with predefined pulse duration parameters that range from 5 to $18 \mathrm{~ms}$. A second system parameter is the protrusion, which is defined as the distance that the heated tip is moved as measured from the edge of the handpiece distance gauge. The protrusion is aimed to acquire better thermal matching between the tip and the tissue without skin perforation (including the Stratum Corneum), along with the process.

Most of the thermal effect is concentrated in the stratum corneum, leading to rapid heat transfer and dehydration of the layer. Gentle elimination of the stratum corneum and desiccation of the upper epidermis establishes a concentration gradient according to Fick's law [19], leading to enhanced drug delivery following Tixel treatment.

The patients in the study did not describe the procedure as painful (VAS score 2.4, SD 0.7). The overall satisfaction of the patients was moderate-high, and objective reduction (as assessed by two independent dermatologists) was significant, as can be seen in Fig. 1. Importantly, no notable adverse effects were reported with this approach. That said, one of the patients did not respond to treatment. The nonresponder had the highest VSS score (10.5) due to the significant height and rope-like bands of their scar. Thermal decomposition alone may not be enough to achieve the necessary drug delivery with in such cases, so alternative methods may be necessary. 
Limitations of this study include the small sample size, the lack of a control group, and the short follow-up period. It is worth noting that these patients refused any other treatment modality due to the pain they had experienced previously with other treatments. We therefore assume that their subjective pain assessments took their experiences with previous treatments into account. This limitation of the study merits further evaluation in a properly controlled manner. Also, this study raises many questions, including: what is the role of heat progression? Is it only a drug delivery enhancement system? Does the heat transfer affect the dermal microvasculature as well? More substantial, randomized, blinded, placebo-controlled studies are needed.

\section{CONCLUSIONS}

Thermomechanical drug delivery of TAC and 5 -FU is safe and effective. This is a promising option for the treatment of keloid scars, particularly in the pediatric population.

\section{ACKNOWLEDGEMENTS}

We thank the participants of the study.

Funding. No funding or sponsorship was received for this study or the publication of this article. The authors funded the article processing charges.

Authorship. All named authors meet the International Committee of Medical Journal Editors (ICMJE) criteria for authorship for this article, take responsibility for the integrity of the work as a whole, and have given their approval for this version to be published.

Disclosures. Ofir Artzi, Amir Koren, Roni Niv, Joseph N. Mehrabi, and Or Friedman have nothing to disclose.

Compliance with Ethics Guidelines. Written consent was received after they were informed of the nature of the procedure.
Consent included the use of photos and data in teaching and medical publications.

Data Availability. This is a retrospective study. The datasets generated and analysed during study are not publicly available due to patient privacy but are available from the corresponding author on reasonable request.

Open Access. This article is distributed under the terms of the Creative Commons Attribution-NonCommercial 4.0 International License (http://creativecommons.org/licenses/ by-nc/4.0/), which permits any noncommercial use, distribution, and reproduction in any medium, provided you give appropriate credit to the original author(s) and the source, provide a link to the Creative Commons license, and indicate if changes were made.

\section{REFERENCES}

1. Ud-Din S, Bayat A. Strategic management of keloid disease in ethnic skin: a structured approach supported by the emerging literature. Br J Dermatol. 2013;169:71-81.

2. Chike-Obi CJ, Cole PD, Brissett AE. Keloids: pathogenesis, clinical features, and management. Semin Plast Surg. 2009;23(3):178-84.

3. Shah VV, Aldahan AS, Mlacker S, et al. 5-Fluorouracil in the treatment of keloids and hypertrophic scars: a comprehensive review of the literature. Dermatol Ther. 2016;6(2):169-83.

4. Juckett G, Hartman-Adams H. Management of keloids and hypertrophic scars. Am Fam Physician. 2009;80(3):253-60.

5. Al-Attar A, Mess S, Thomassen JM, Kauffman CL, Davison SP. Keloid pathogenesis and treatment. Plast Reconstr Surg. 2006;117:286-300.

6. Kim S, Choi TH, Liu W, Ogawa R, Suh JS, Mustoe TA. Update on scar management: guidelines for treating Asian patients. Plast Reconstr Surg. 2013;132:1580-9.

7. Gold MH, McGuire M, Mustoe TA, Pusic A, Sachdev M, Waibel J, Murcia C. International Advisory Panel on Scar Management. Updated international clinical recommendations on scar management: part 
2-algorithms for scar prevention and treatment. Dermatol Surg. 2014;40:825-31.

8. Muneuchi G, Suzuki S, Onodera M, Ito O, Hata Y, Igawa $\mathrm{HH}$. Long-term outcome of intralesional injection of triamcinolone acetonide for the treatment of keloid scars in Asian patients. Scand J Plast Reconstr Surg Hand Surg. 2006;40:111-6.

9. Mishra S. Safe and less painful injection of triamcinolone acetonide into a keloid-a technique. J Plast Reconstr Aesthet Surg. 2010;63:e205.

10. Chuang GS, Rogers GS, Zeltser R. Poiseuille's law and large-bore needles: insights into the delivery of corticosteroid injections in the treatment of keloids. J Am Acad Dermatol. 2008;59:167-8.

11. Waibel JS, Wulkan AJ, Shumaker PR. Treatment of hypertrophic scars using laser and laser-assisted corticosteroid delivery. Lasers Surg Med. 2013;45:135-40.

12. Cavalié $\mathrm{M}$, Sillard L, Montaudié H, Bahadoran P, Lacour JP, Passeron T. Treatment of keloids with laser-assisted topical steroid delivery: a retrospective study of 23 cases. Dermatol Ther. 2015;28:74-8.

13. Issa MC, Kassuga LE, Chevrand NS, Pires MT. Topical delivery of triamcinolone via skin pretreated with ablative radiofrequency: a new method in hypertrophic scar treatment. Int J Dermatol. 2013;52:367-70.

14. Bloom BS, Brauer JA, Geronemus RG. Ablative fractional resurfacing in topical drug delivery: an update and outlook. Dermatol Surg. 2013;39:839-48.

15. Uchida Y, Park K. Stratum corneum. In: Kabashima $\mathrm{K}$, editor. Immunology of the skin. Tokyo: Springer; 2016. p. 15-30. https://doi.org/10.1007/978-4-43155855-2_2.

16. Warner RR, Myers MC, Taylor DA. Electron probe analysis of human skin: determination of the water concentration profile. J Invest Dermatol. 1988;90:218-24.

17. Stockdate M. Water diffusion coefficients versus water activity in stratum corneum: a correlation and its implications. J Soc Cosmetic Chemists. 1978;29:625-39.

18. Wildnauer RH, Bothwell JW, Douglass AB. Stratum corneum biomechanical properties. I. Influence of relative humidity on normal and extracted human stratum corneum. J Investig Dermatol. 1971;56(1): 72-8.

19. Cengal YA. Heat transfer: a practical approach. 2nd ed. New York: McGraw-Hill; 2002. 